\title{
Randomized Informational Intervention and Adult Park Use and Park-Based Physical Activity in Low-Income, Racially Diverse Urban Neighborhoods
}

\author{
Noah Wexler, Yingling Fan, Kirti V. Das, and Simone French
}

\begin{abstract}
Background: Neighborhood parks are important locations to encourage and stimulate physical activity (PA) among the urban population. This study aims to evaluate the impact of an informational intervention on adult park use and PA behaviors in 3 lowincome, racially diverse urban neighborhoods in Minneapolis, MN. Method: The study employed a household-level randomized controlled trial and collected baseline and follow-up data from 171 participants. Within each neighborhood, participants were randomized to an informational intervention or to a no-intervention comparison. Intervention households received monthly, neighborhood-specific newsletters about park-based PA opportunities, park program brochures, trail maps, and activity guides. Results: The average treatment effect of the newsletter intervention was positive yet moderated by respondent age. For a 20 -year-old resident, treatment was associated with $0.97(P<.05)$ additional park visits and $31.24(P<.05)$ additional minutes of park-based PA over a 3-day recall period. For 40 -year-old respondents, these positive effects are smaller at $0.36(P<.05)$ additional visits and 4.66 $(P<.05)$ additional minutes, respectively. Conclusions: An intervention to increase awareness about park-based PA opportunities and benefits increased self-reported park visits and in-park PA among adults who lived in low-income, racially diverse neighborhoods.
\end{abstract}

Keywords: intervention study, built environment, municipal parks, outdoor space, active recreation

Parks can improve local population health in urban neighborhoods by providing outdoor physical activity (PA) opportunities. ${ }^{1,2}$ PA has direct physical and mental health benefits and is associated with a reduced risk of many chronic diseases. ${ }^{3-5}$ In addition, parks can potentially improve public health through biological stress reduction mechanisms and the enhancement of social interactions. ${ }^{6-8}$ Given the multiple health benefits, parks can be useful when addressing health disparities. First, parks are often a community's "living room," and therefore may be a promising place to penetrate for community-wide behavior changes in poor, underresourced communities. ${ }^{9,10}$ Second, public parks and recreation services can provide free or low-cost PA facilities and programs at the community level that can be broadly accessible to low-income residents, potentially reducing disparities in PA and health outcomes. ${ }^{1-13}$ However, evidence suggests that parks are often underutilized in low-income neighborhoods. ${ }^{14-16}$ This points to the undertapped potential of parks and park programs and services to better address health disparities in low-income, racially diverse communities.

Adult park use behavior is often dependent on people's information levels and awareness of park services. Municipalities could promote and encourage healthy park use by increasing awareness about the benefits of park-based PA and by publicizing convenient PA opportunities. ${ }^{17,18}$ However, although increasing research has been conducted to investigate how interventions of adding park PA amenities (eg, PA equipment) and adding PA programs in parks (eg, park-based fitness classes) may affect park use and park-based $\mathrm{PA}, 15,19$ there is limited research on the impacts of informational and

Wexler and Fan are with the Humphrey School of Public Affairs, University of Minnesota-Twin Cities, Minneapolis, MN, USA. French is with the School of Public Health at the University of Minnesota-Twin Cities. Das is with the Department of Civil and Environmental Engineering, Princeton University, Princeton, NJ, USA. Fan (yingling@umn.edu) is corresponding author. outreach intervention programs on promoting park use and parkbased PA. Among the few studies that included an informational intervention component, Bush et $\mathrm{a}^{20}$ used a randomized controlled trial (RCT) design and found that a park-based physical fitness and nutrition education improved PA performance and nutrition knowledge in overweight minority children. Cohen et al ${ }^{17}$ used a RCT design and found that park-based marketing and outreach efforts increased park-based PA behavior in 50 racially diverse neighborhoods in Los Angeles. It is worth noting that the actual formats of the marketing and outreach efforts in Cohen et $\mathrm{al}^{17}$ were determined by park directors and/or park advisory boards rather than the researchers. Three types of marketing and outreach efforts were evaluated, including (1) signage to improve the park image (eg, banners, bulletin boards, floor mats, staff shirts, and table covers); (2) promotional incentives like water bottles, bags, or park-branded key chains or individually targeted email communications; and (3) outreach and support for group activities. Among the 3 types, signage was found to be most effective to promote park-based PA.

This study contributes to the limited literature on the effects of informational interventions on park-based adult PA behavior by using a RCT featuring a newsletter campaign in 3 low-income, racially diverse neighborhoods in Minneapolis, MN. Specifically, we examine how a series of informational newsletters advertising already existing park amenities, features, and services affected individual survey respondents' park visitation frequency and amount of park-based PA.

\section{Methods}

\section{Study Setting}

Figure 1 shows the location of the 3 study neighborhoods in Minneapolis, $\mathrm{MN}$, which are home to a diverse array of park services. The Harrison neighborhood includes a portion of the 
759-acre Theodore Wirth Park (which is Minneapolis's largest regional park) and the 6.9-acre Harrison Park. The Powderhorn neighborhood contains the 65.88-acre Powderhorn Park. The Phillips neighborhood contains several small parks including the 6.46-acre East Phillips Park and the 6.27-acre Stewart Park. Despite the differences in park size, due to the long-term efforts by the Minneapolis Park and Recreation Board (MPRB) to increase equity in parks and recreation services, the 3 study neighborhoods have access to similar amenities including community centers, baseball fields, basketball courts, soccer fields, softball fields, tennis courts, picnic areas, playgrounds, wading pools, walking paths, and restrooms. The Theodore Wirth Park, being a regional park, also includes hiking and biking paths, a golf course, and numerous winter activities such as sledding/tubing, snowboarding, snowshoeing, and cross-country skiing.

The study neighborhoods offer opportunities to examine park use behavior in low-income, racially diverse urban settings (Table 1). As shown in Table 1, the proportion of white residents in the 3 neighborhoods is significantly lower when compared with Minneapolis as a whole. Phillips and Powderhorn have a larger

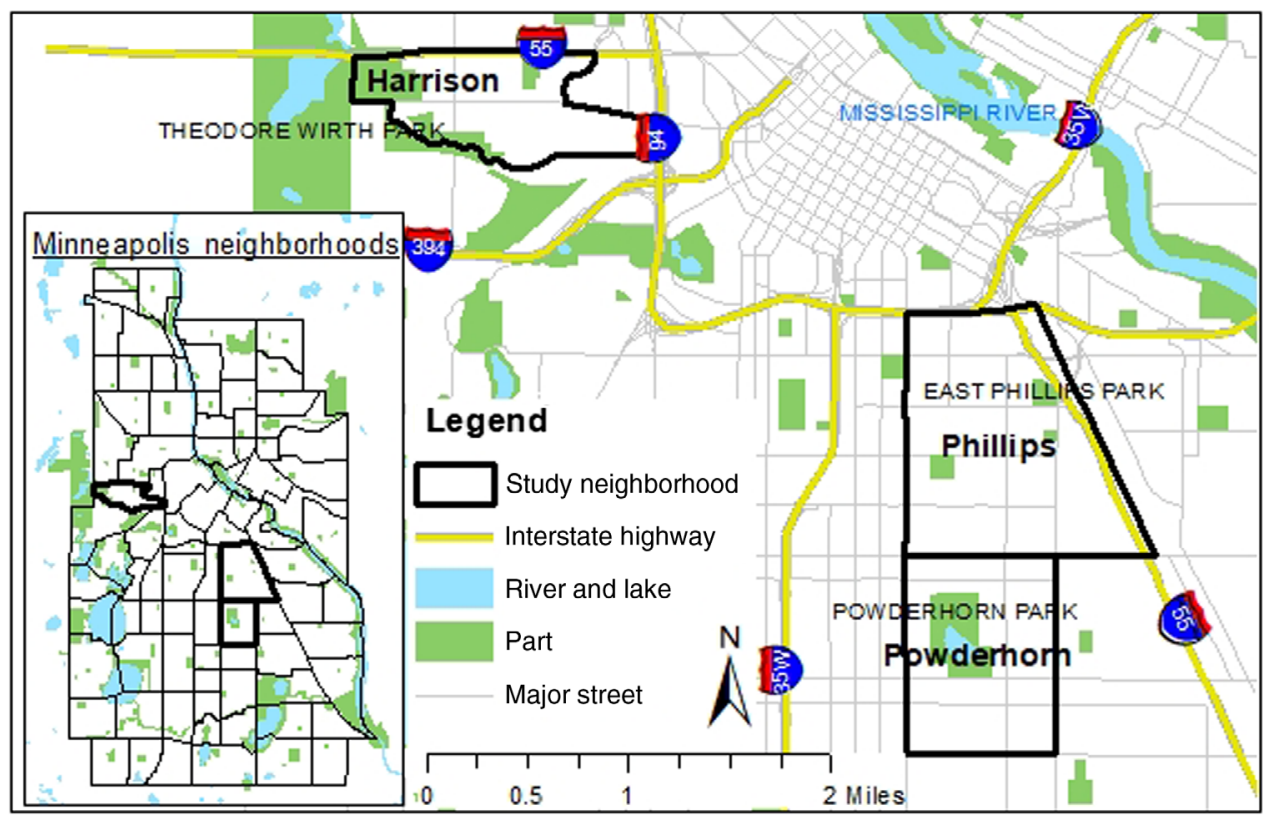

Figure 1 - Study neighborhoods.

Table 1 Demographics (Census, 2010) and Income Estimates (American Community Survey, 2009) of Study Neighborhoods

\begin{tabular}{lcccc}
\hline Demographic variables & Minneapolis & Phillips & Powderhorn & Harrison \\
\hline Race/ethnicity, $\%$ & 70 & 29 & 55 & 32 \\
White & 16 & 29 & 15 & 40 \\
Black or African American & 2 & 13 & 3 & 2 \\
American Indian and Alaska Native & 5 & 3 & 2 & 17 \\
Asian & 0 & 0 & 0 & 0 \\
Native Hawaiian/other Pacific Islander & 5 & 21 & 18 & 4 \\
Some other race & 3 & 6 & 6 & 5 \\
Two or more races & 9 & 33 & 26 & 8 \\
Hispanic & & & & \\
Gender, $\%$ & 50 & 52 & 50 & 50 \\
Male & & & & 17 \\
Income, $\%$ & 11 & 23 & 8 & 21 \\
Less than $\$ 10,000$ & 18 & 21 & 22 & 40 \\
$\$ 10,000$ to $\$ 24,999$ & 25 & 26 & 26 & 10 \\
$\$ 25,000$ to $\$ 49,999$ & 18 & 17 & 24 & 4 \\
$\$ 50,000$ to $\$ 74,999$ & 11 & 8 & 10 & 9 \\
$\$ 75,000$ to $\$ 99,999$ & 18 & 5 & 10 & \\
$\$ 100,000$ or more & & & & \\
\hline
\end{tabular}


proportion of Hispanic residents; and Harrison has larger proportion of black and Asian residents compared with Minneapolis. Phillips also has a significantly larger proportion of American Indian residents compared with rest of the city. Additionally, all 3 neighborhoods have slightly higher proportions of low-income (under $\$ 25,000$ ) residents than the whole city.

\section{Experimental Design}

Between September and November 2010, the MPRB conducted a Survey of Parks, Leisure-time Activity, and Self-reported Health (SPLASH) of 433 households across the 3 neighborhoods. Survey households were determined by randomly selecting Census blocks within each neighborhood and attempting to reach all residents on a given block. The 2010 SPLASH served as the baseline data, which gathered data on a single adult from each household about respondent demographics, perceptions of park services, and recalled park visit frequency and park-based PA duration over the previous 3 days. Park visit frequency was captured by a count of total visits to a park over the 3-day recall period, and park-based PA was captured by the total minutes spent engaging in PA at a public park during the 3-day recall period.

Of the 433 households, 6 households had incomplete home address information recorded in the baseline data and were excluded from randomization in the follow-up intervention study in 2011. The remaining 427 households were randomized so that $50 \%$ of them $(214 / 427)$ were expected to receive treatment in the form of informational newsletters and promotional materials about nearby parks and the health benefits of park use between May and August 2011. However, due to high neighborhood turnover rates and the need to find the same persons in the baseline survey to participate in the follow-up, the research team was only able to confirm 91 adults out of the 214 intervention home addresses who had participated in the baseline survey, resulting in a $57 \%$ loss to follow-up. Of the 213 control home addresses, the research team was only able to confirm 80 adults who had participated in the baseline survey, resulting in a $62 \%$ loss to follow-up. The high loss to follow-up could be a combination of high turnover rates in lowincome neighborhoods and the limited home visits (up to 3 due to funding constraints) that the research team made to track down the persons who participated in the baseline survey. It is possible that the loss to follow-up would have been smaller if the research team had made more home visits. See Supplemental Material (available online) for a Consolidated Standards of Reporting Trials (CONSORT) flow diagram illustrating the randomization and follow-up process.

Each confirmed adult in the treatment group $(n=91)$ received 4 monthly informational and promotional packets over the course of the summer between May and August 2011. The information packets were hand delivered by student researchers to each home monthly. For the first information packet, the student researchers were required to have a face-to-face conversation. The remaining 3 packets were either delivered to the respondent in person or left at their home depending on their availability at the time of delivery.
In October and November 2011, the follow-up survey of the confirmed adults in both treatment $(n=91)$ and control groups $(\mathrm{n}=80)$ was administered. Due to the large loss to follow-up, we compared baseline outcomes between the study sample (confirmed treatment and control groups) and the group lost to follow-up. We find no statistically significant differences, as shown in Table 2 . We also checked for differences in sociodemographic composition. The comparison shows relatively similar gender and race distributions between the treatment and control groups. However, age distribution shows significant differences. As a result, we limit our analysis to respondents aged 18-70 years at the time of follow-up because 4 respondents aged 70 years and older were in the control group, but the highest age of the treatment group was 66 years. Thus, the final study group included the 167 individuals surveyed both years who were between the ages of 18 and 70 during the treatment year.

\section{The Newsletter Intervention Program}

The team created a total 4 newsletters that were distributed monthly. All 4 newsletters, while tailored to each neighborhood, were standardized in terms of the broader contents. The contents of each newsletter were based on research conducted on similar interventions, project team meetings, and input from MPRB staff in charge of day-to-day operation of the parks and community centers in the study neighborhoods. Contents of newsletters included locations of parks and trails in each neighborhood, list of amenities available, programs offered at parks, special events, links to helpful pages on the MPRB website, and fun facts about the Minneapolis park system. Figure 2 shows one of the newsletters used for the intervention.

The treatment was designed to generate interest in neighborhood park services and encourage participants to use park services more frequently. Information was targeted at the neighborhood level to reduce problems associated with overly general mass media style campaigns. For instance, newsletters featured upcoming events held in nearby parks and programs at nearby recreational centers. Sections on the bottom right corner of Figure 2 display these features for a newsletter passed out to Powderhorn neighborhood study participants. The tailored focus of each newsletter emphasized nearby amenities and programming based on each participant's neighborhood ensuring that treatment reflected the differences between each neighborhood's parks. Furthermore, the contents of the newsletter targeted the adult population in general. There were no adult population subsegments (eg, women, older adults, or other groups) that were specifically targeted. We hypothesized that treatment group membership was associated with increases in self-reported park visitation and park-based PA, compared with the control group. In this context, park visitation represents the extensive margin of park use, while park-based PA represents an intensive margin of park use that has direct health effects. Note that the measurement of park visitation and park-based PA behavior was about people's park use in general and not specific to the respondents' neighborhood parks.

Table 2 Differences in Baseline Outcome-Study Sample Versus Lost to Follow-Up

\begin{tabular}{lcccc}
\hline Variable & $\begin{array}{c}\text { Mean (study sample) } \\
\mathbf{n = 1 7 1}\end{array}$ & $\begin{array}{c}\text { Mean (lost to follow-up) } \\
\mathbf{n = 2 6 2}\end{array}$ & Difference & SE \\
\hline Total 3-day recall park visits (visits) & 1.287 & 1.187 & 0.010 \\
Total 3-day recall physical activity (minutes) & 65.409 & 70.542 & 0.150 \\
\hline
\end{tabular}




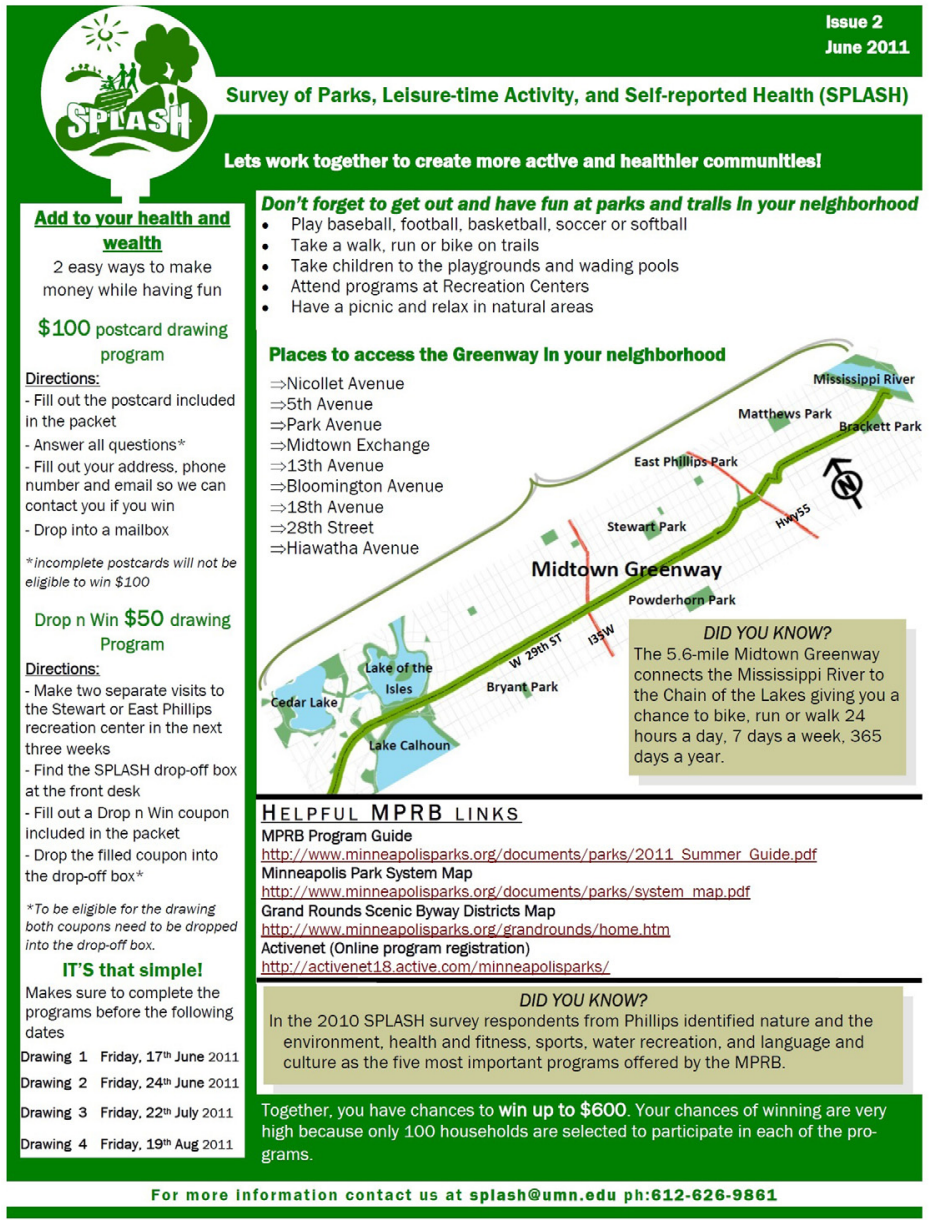

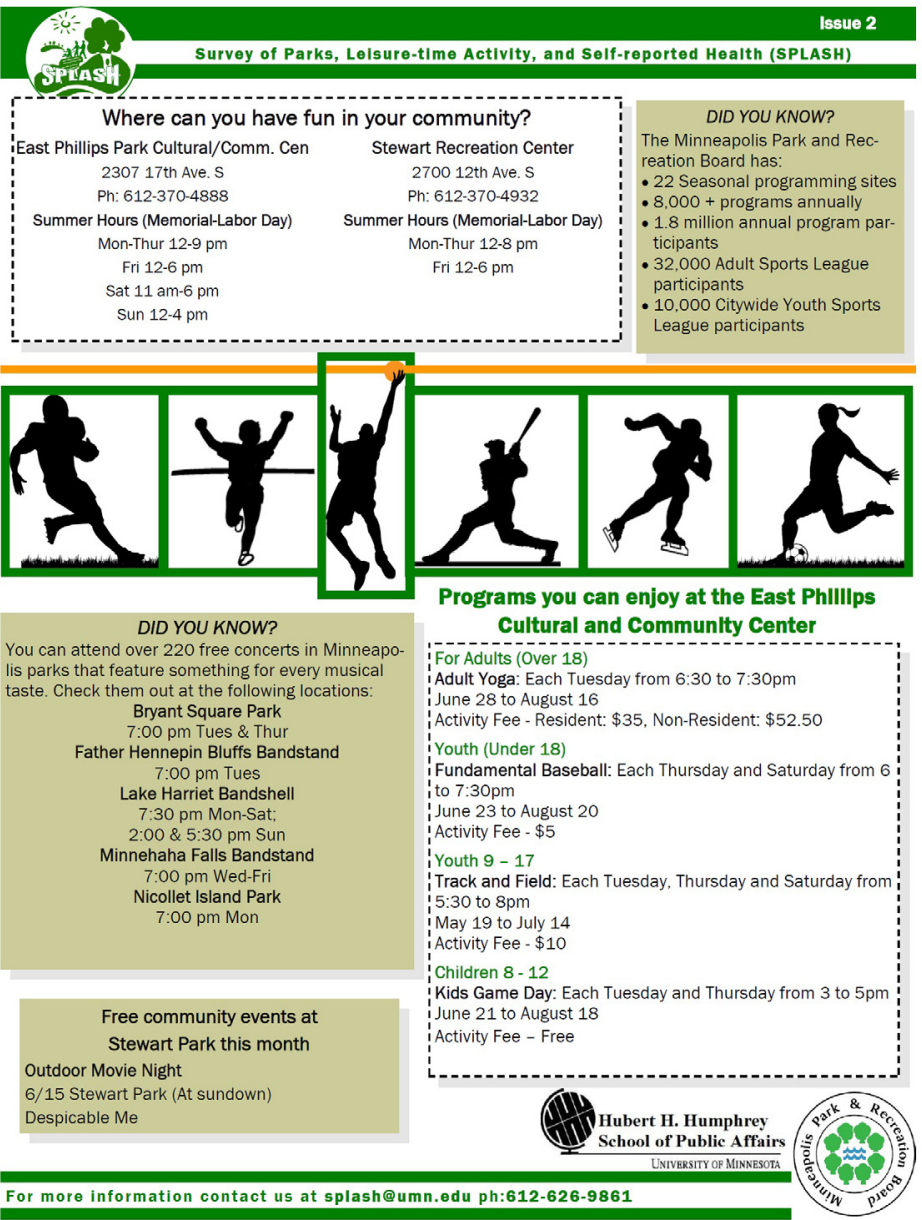

Figure 2 - Interventional newsletter example.

The following language was used when asking about park-based PA duration in the past 3 days: "How many minutes did you spend on moderate physical activity, vigorous physical activity, and muscle strengthening activity on DAY $1 / 2 / 3$ at parks and trails, including recreation centers or exercise rooms in parks?" The consent process, newsletter intervention program, and survey instruments were approved by the Human Subjects Committee at the University of Minnesota Institutional Review Board on August 19, 2010.

\section{Study Variables}

Table 3 shows descriptive statistics of the variables used in our study between the treatment and control groups. The dates associated with each participant's 3-day recall period were used to derive objective weather information of these dates, using data from the Minneapolis-St. Paul International Airport Weather Station daily records, which is publicly available at the National Climatic Data Center. Because there were slight differences in the 2 groups' demographic compositions, 3-day recall period weather, and average life circumstances, as illustrated in the 2 panels of covariates included in Table 3, it was necessary to control for such factors in regression models. Additionally, 2010 baseline outcomes between the 2 groups were different, necessitating their inclusion as control variables to avoid treatment effect estimate bias associated with regression to the mean. ${ }^{21}$ The number of observations is occasionally inconsistent between variables because unanswered SPLASH questions were dropped for the nonresponsive participant.

\section{Statistical Analysis}

Given the hypotheses above, we compared outcomes between 2010 and 2011 for 2 dependent variables. To assess the effect of the SPLASH behavioral intervention on park visits and parkbased PA, we regress 2010-2011 change scores for both dependent variables on a binary variable indicating treatment group membership and several control variables. Using change scores accounts for each respondent's baseline values and allows the data to fit a more normal distribution. At the recommendation of Vickers and Altman $^{22}$ and Twisk et al, ${ }^{21}$ we control for regression to the mean by including 2010 baseline outcomes as a control variable. As Twisk et $\mathrm{al}^{21}$ point out, this approach is analogous to analysis of covariance, with covariate coefficients capturing correlations between the covariate and the posttreatment outcome, as opposed to the change score. However, in our context, the use of change scores reduces the need to use nonlinear specifications because specifying change scores as dependent variables helps hold the ordinary least squares normality assumption and allows for more consistent estimation. 


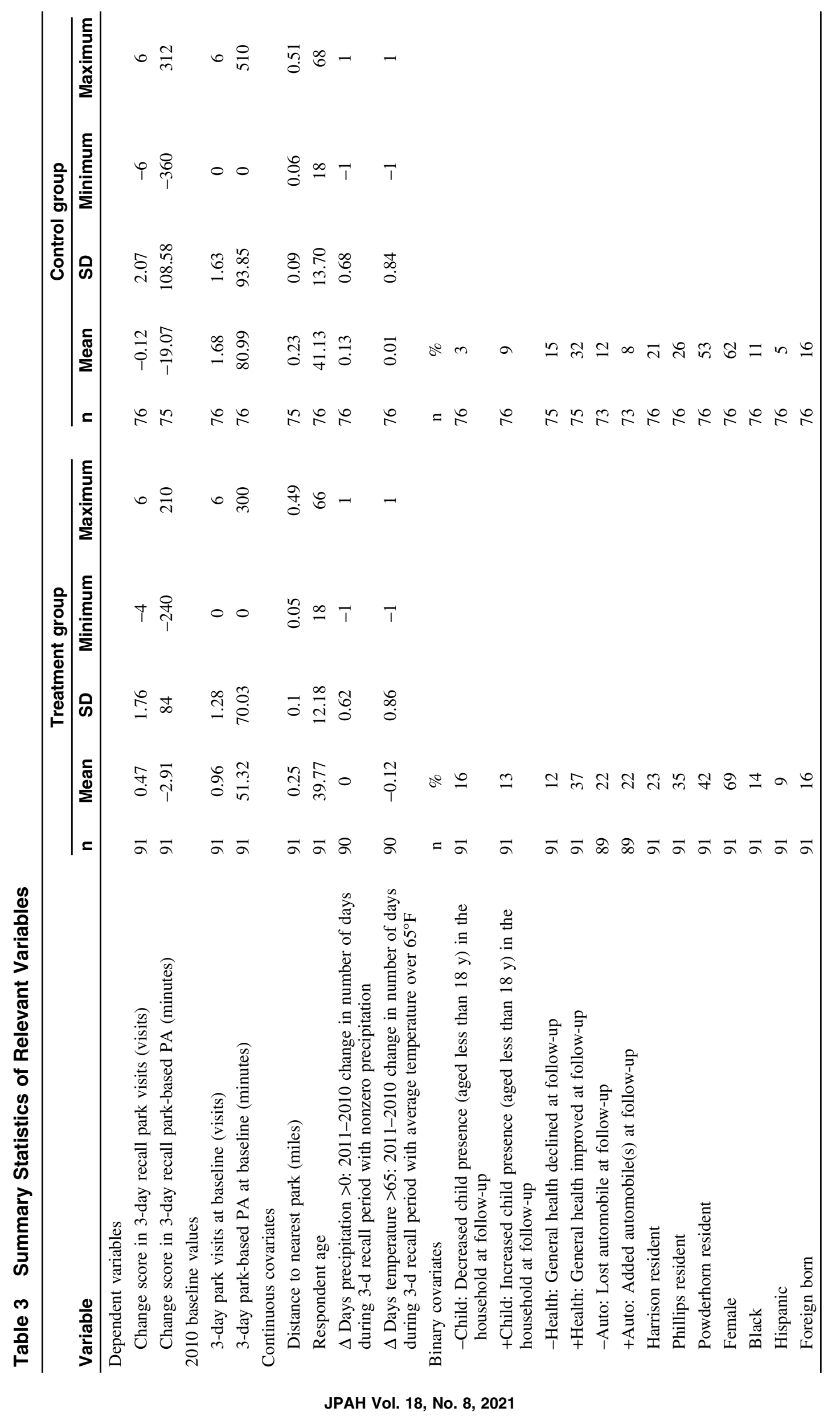


While the inclusion of additional controls is not essential to analyze data from RCTs, it allows for more nuanced analysis, especially when treatment might interact with individual participant characteristics. ${ }^{23}$ Thus, we include several control covariates in both models. First, we control for the effect of other potential phenomena that could alter park use behavior such as changes in auto ownership, changes in the number of children aged less than 18 years living in a respondent's household, and changes in a respondent's self-reported general health. Each of these effects is incorporated into regression models using 2 binary variables, one representing an increase in the relevant measure and the other representing a decrease. To capture unobservable circumstantial changes associated with a respondents' neighborhood, we include binary variables capturing a participant's neighborhood. Additionally, the timing of each survey could affect 3-day recall scores because of local weather conditions during the previous 3-day time span before SPLASH administration. Thus, we control for 20112010 changes in the number of 3-day recall days with nonzero precipitation and with average temperatures over $65^{\circ} \mathrm{F}$.

Finally, to capture the effect of differences in composition between the treatment and control groups, we include several demographic binary variables, as well the distance of each respondent's home from the nearest park. In this vector of covariates, we include respondent age and an interaction term between the treatment binary variable and respondent age. This interaction term captures the heterogeneous effect of the behavioral intervention on individuals of different ages. Figure 3 below shows interaction in the data between age and treatment for both dependent variables, necessitating the inclusion of an interaction term to fully statistically estimate a treatment effect.

Thus, our final models are estimated according to the below equation. Each model uses heteroskedasticity consistent standard errors to ensure robustness. Huber-White standard errors were used instead of cluster-robust estimators because the number of clusters (3 neighborhoods) was too small, because randomization occurred within neighborhoods, and because within-neighborhood intraclass correlation was low. Specifically, intraclass correlation was estimated less than $10 \%$ of total variation for change scores in park visits and near $0 \%$ of the variation in change scores in park-based
PA. All statistical analysis was conducted using Stata SE (version 16.0, manufactured by StataCorp in College Station, TX) in 2019.

$$
\begin{aligned}
\Delta \text { Outcome }_{2011-2010}= & \beta_{0}+\beta_{1} \text { treatment }+\beta_{2} \text { treatment } \times \text { age } \\
& +\beta_{3} \text { baseline }_{2010}+\beta_{4} \text { age }+\gamma \text { controls }+\varepsilon .
\end{aligned}
$$

\section{Results}

Table 4 displays results of the 2 main ordinary least squares models estimating the treatment effect on change scores of 3-day recall park visits and park-based PA. Both models control for baseline 2010 outcomes, year-to-year circumstantial effects, and demographics. We also report coefficients in year-to-year differences in average precipitation and temperature during the 3-day recall period for park visits and park-based PA. The sample sizes differ slightly between both models because not all respondents answered all questions, and respondents with blank responses were dropped from analysis.

The average treatment effect is statistically significant at $95 \%$ confidence for both models, controlling for a full set of covariates. Additionally, the interaction between respondent age and treatment is associated negatively with change scores and is statistically significant at $90 \%$ confidence. Phillips residents experienced lower increases in year-to-year 3-day recall park visits and PA than residents in Powderhorn and Harrison, perhaps reflecting the Phillips neighborhood's lack of one single large park with a wide range of amenities in the same park. Additionally, East Phillips Park underwent construction during the study period, likely limiting public use and drawing fewer neighborhood visits. Respondents who reported declines in general health also saw less pronounced increases in park visits and park-based PA durations. Hispanic respondents also reported lower outcomes compared with non-Hispanic participants. This finding may be due to Hispanics being less sensitive to an informational intervention that was delivered in English only. However, this finding merits further research given the limited number of Hispanic participants in the sample. Our sample included a total of 12 Hispanic participants, including 8 in the intervention group and 4 in the control group.
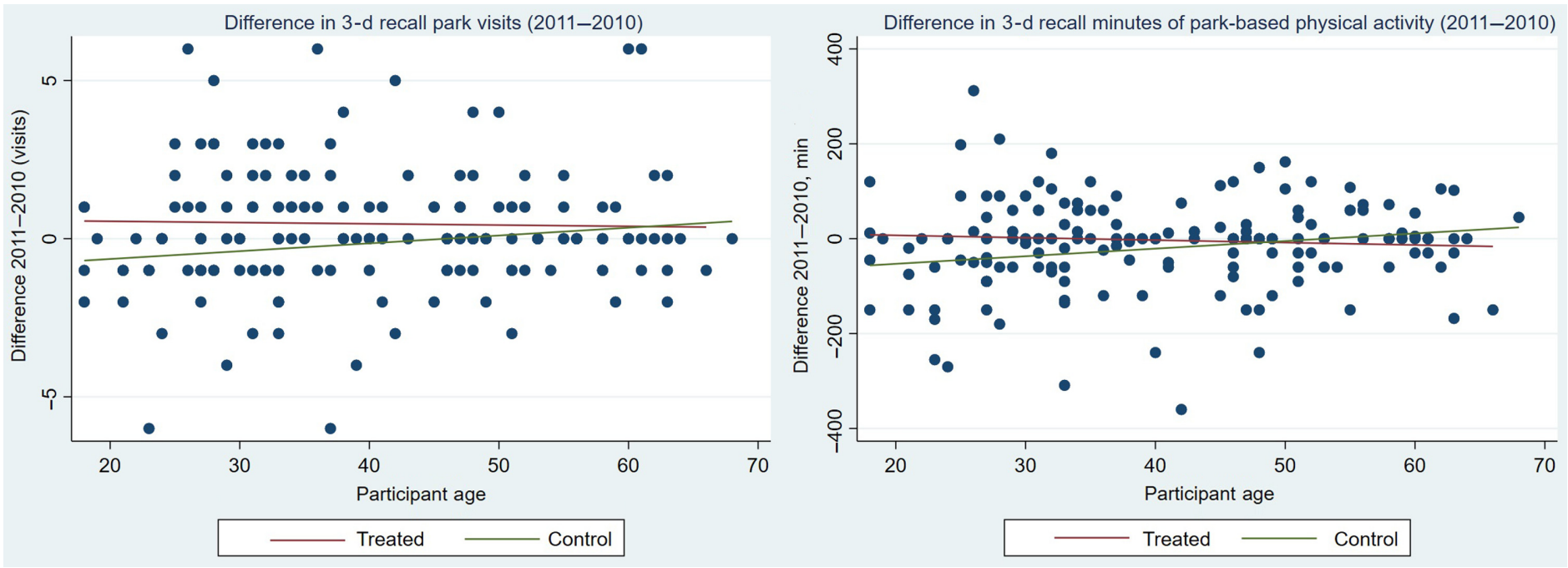

Figure 3 - Scatter plots and fitted lines-interaction of age and treatment. Note that the relatively flat line in the figures above represents the treated group and the slightly upward line in the figures represents the control group. 
Table 4 Results From Regressions of Park Use Outcomes on Treatment and Covariates

\begin{tabular}{|c|c|c|c|c|}
\hline \multirow[b]{3}{*}{ Dependent variable } & \multicolumn{2}{|c|}{ 1: OLS } & \multicolumn{2}{|c|}{ 2: OLS } \\
\hline & \multicolumn{2}{|c|}{$\begin{array}{l}\text { Change score in 3-day recall } \\
\text { park visits (total visits) }\end{array}$} & \multicolumn{2}{|c|}{$\begin{array}{l}\text { Change score in 3-day recall } \\
\text { park-based PA (minutes) }\end{array}$} \\
\hline & Coefficient & $P$ value & Coefficient & $P$ value \\
\hline \multicolumn{5}{|l|}{ Treatment/baseline effects } \\
\hline Treatment & $1.592 * *$ & .031 & $57.82 * *$ & .09 \\
\hline Age $\times$ treatment & $-0.0308^{*}$ & .085 & $-1.329 *$ & .093 \\
\hline 2010 baseline & $-0.646^{* * *}$ & 0 & $-0.774^{* * *}$ & 0 \\
\hline \multicolumn{5}{|c|}{ Circumstantial/neighborhood effects } \\
\hline -Child & 0.270 & .492 & 12.77 & .517 \\
\hline +Child & -0.277 & .385 & -12.00 & .309 \\
\hline -Health & $-0.866^{* * *}$ & .005 & $-44.93^{* * *}$ & 0 \\
\hline+ Health & -0.0157 & .955 & -16.81 & .135 \\
\hline -Auto & 0.286 & .454 & -2.776 & .872 \\
\hline+ Auto & 0.123 & .684 & -1.597 & .906 \\
\hline$\Delta$ Precipitation days & 0.149 & .426 & 5.152 & .533 \\
\hline$\Delta$ Warm temperature days & 0.0211 & .885 & 3.576 & .574 \\
\hline Harrison & 0.530 & .181 & -9.870 & .489 \\
\hline Phillips & $-0.777^{* * *}$ & .009 & $-27.62^{*}$ & .059 \\
\hline \multicolumn{5}{|l|}{ Demographics } \\
\hline Age & 0.0168 & .209 & 0.900 & .113 \\
\hline Distance to nearest park & -1.868 & .134 & $-114.4^{* *}$ & .018 \\
\hline Female & 0.146 & .563 & 4.268 & .718 \\
\hline Black & -0.179 & .656 & 9.443 & .616 \\
\hline Hispanic & $-1.347^{* * *}$ & .001 & $-48.90 * * *$ & .009 \\
\hline Foreign born & 0.376 & .237 & 21.68 & .178 \\
\hline Constant & 0.712 & .352 & 46.17 & .139 \\
\hline \multicolumn{5}{|l|}{ Summary } \\
\hline Observations & 159 & & 158 & \\
\hline$R$-squared & .461 & & .569 & \\
\hline Neighborhood ICC & .08359 & & 0 & \\
\hline
\end{tabular}

Abbreviations: ICC, intraclass correlation; OLS, ordinary least squares; PA, physical activity. Note: Robust SEs used to determine statistical significance. Neighborhood ICC was statistically insignificant at $95 \%$ confidence for both dependent values. Coefficients with $P<.1$ are given in bold.

$* * *$ Significance at $99 \%$ confidence, $* *$ at $95 \%$, and *at $90 \%$.

Future research may oversample racial and ethnic minorities to further investigate whether informational interventions would be less effective among some racial and ethnic minorities than others, and whether multilingual interventions could improve outcomes across racial and ethnic minorities.

The heterogeneity of treatment effect by age is notable and statistically significant at $90 \%$ confidence. Table 5 provides average treatment effect estimates by age, calculated by subtracting the coefficient on age $\times$ treatment from the coefficient on treatment. Increasing respondent age moderates the effect of treatment such that, by age 50 years, treatment is associated with reductions in 3day recall park visits and park-based PA.

\section{Discussion and Conclusions}

This research contributes to the limited literature on the impacts of individual-level informational interventions on park use and parkbased PA behaviors. Because this study finds that informational interventions can successfully induce positive park-related health outcomes, its findings align with the conclusions of Cohen et al, ${ }^{17}$
Table 5 Average Effect of Informational Intervention by Age

\begin{tabular}{|c|c|c|}
\hline & 1: OLS & 2: OLS \\
\hline Age & $\begin{array}{l}\text { Change score } \\
\text { in 3-day recall park } \\
\text { visits (total visits) }\end{array}$ & $\begin{array}{l}\text { Change score } \\
\text { in 3-day recall park- } \\
\text { based PA (minutes) }\end{array}$ \\
\hline 20 & 0.976 & 31.24 \\
\hline 30 & 0.668 & 17.95 \\
\hline 40 & 0.36 & 4.66 \\
\hline 50 & 0.052 & -8.63 \\
\hline 60 & -0.256 & -21.92 \\
\hline
\end{tabular}

Abbreviations: OLS, ordinary least squares; PA, physical activity.

Cavill and Bauman, ${ }^{18}$ and Bush et al. ${ }^{20}$ Furthermore, this study additionally shows that tailoring messaging at a highly localized level can increase park use and at-park PA. Additionally, it helps explain why parks are often underutilized places for PA. ${ }^{9}$ 
This study also provides the first evidence in the literature that age plays a significant role in moderating the impacts of informational interventions targeting the promotion of park use and parkbased PA. The newsletter campaign was found to be more effective among younger adults than among older adults. It is possible that older residents may have long-established PA and park use habits such that the informational intervention less effectively altered their behavior. In addition, our sample size is small and the interactive effect of age and treatment is only significant at the $90 \%$ confidence level. The finding on the interaction effect may not be generalizable to other study settings. Future research is recommended to use larger samples across multiple cities to examine the generalizability of the interactive effect of age and treatment. In addition, correlates of age such as years of residency and time-use variables could explain the effect and allow for more acute policy interventions such as better tailored information and outreach methods based on these potentially age-confounding factors. Regardless, this finding underscores the importance of conducting population-specific examinations, which will provide more accurate and comprehensive understanding of the park-based behavior intervention effects across population groups.

The distance between a participant's household and the nearest park only affected results for 3-day recall park-based PA, but not park visits. A closer examination of this effect in future studies may allow for more tailored interventions. It is possible that people who live farther from parks engage in PA in the process of traveling to parks and thus use parks for other leisure purposes. It is also possible that parks may be less attractive PA locations when other PA locations are closer in proximity to one's place of residence.

This study has several major limitations. First, the large loss to follow-up $-57 \%$ in the treatment group and $62 \%$ in the control group-introduces concerns about the validity of the study findings. Although we made efforts to remove and control for the heterogeneity in sociodemographic composition between the treatment and control groups (eg, the removal of 4 adults aged $70 \mathrm{y}$ and older in the control group and controlling for age, gender, and race), the efforts may not be sufficient to avoid bias. It is possible that people who lost to follow-up were less connected to their neighborhoods and less likely to have visited parks as a result of the intervention. The observed positive effects of the information intervention may be overestimated due to possible selection bias. Second, 3-day recall park visits and park-based PA are relatively volatile metrics of general park use. Although the inclusion of weather controls helps to improve the reliability of 3-day recall estimates, there may be other omitted variables that affect the reliability of the 3-day recall measures. Third, our final study sample-while demographically diverse-is disproportionately female and white. The percentage of black participants in the final sample was 14 in the treatment group and 11 in control group, which was significantly lower than the percentage of black residents in the study neighborhoods (shown as $15 \%-40 \%$ in Table 1). The underrepresentation of residents of color in the final sample is a weakness of the study. Future research should examine the gap in outcomes associated with Hispanic participants and identify potential explanations. It is possible that multilingual information interventions are necessary to ensure effective interventions across race and ethnic minorities. Future research should also oversample racial and ethnic minorities to ensure the generalizability of the findings associated with minority population groups. Additionally, while limiting the study to the Phillips, Powderhorn, and Harrison neighborhoods provides important insight into how residents of economically diverse park-rich neighborhoods respond to informational behavioral intervention, a study conducted across an entire city could identify more heterogeneous affects across neighborhoods. For instance, research could examine how residents of different socioeconomic status may respond to similar informational interventions in neighborhoods with different park resources. Additionally, effects could be interacted with measures of park quality. It is possible that such interventions may be less successful if park quality is low. Furthermore, the 3 study neighborhoods all have ample park infrastructure. Further research can and should be conducted to investigate the effectiveness of informational interventions on park use and park-based PA across urban neighborhoods with different levels of park accessibility. Finally, the paper-based delivery mechanism of the informational intervention may be outdated and labor intensive. The same information may be delivered electronically. Future research may compare paper-based newsletter campaigns with digital campaigns to check whether the delivery mechanism may affect the effectiveness of the intervention.

Despite the major limitations, evidence from this RCT demonstrates that targeted and tailored informational interventions can spur increased park use. The positive effects of the informational intervention are especially evident among residents aged 50 years and younger of low-income neighborhoods with parks in close proximity. Simply providing digestible information to residents significantly increases their use of surrounding park facilities, amenities, and services. This is an important finding that further confirms the effectiveness of informational interventions to increase PA. ${ }^{24}$ More importantly, this study confirms that parks are a promising resource for community-wide informational interventions that aim to increase PA in poor, underresourced communities. While cities have been prevented from buying new parkland due to budget shortfalls, ${ }^{25}$ this study suggests that cities can increase park use and park-based PA without substantial expenditure. Municipal policymakers are recommended to provide more informational resources for park-related community outreach activities.

\section{Acknowledgments}

The authors would like to thank the Minneapolis Parks and Recreation Board for their help in informing, designing, and translating the outreach materials provided to the treatment group. Additionally, the authors would like to thank the Children, Youth, and Families Consortium, the Center for Urban and Regional Affairs, and the Obesity Prevention Center at the University of Minnesota, Twin Cities for providing funding support. The authors have no conflict of interest disclosures.

\section{References}

1. Bedimo-Rung AL, Mowen AJ, Cohen DA. The significance of parks to PA and public health: a conceptual model. Am J Prev Med. 2005; 28:159-168. PubMed ID: 15694524 doi:10.1016/j.amepre.2004. 10.024

2. Sallis JF, Cerin E, Conway TL, et al. Physical activity in relation to urban environments in 14 cities worldwide: a cross-sectional study. Lancet. 2016;387(10034):2207-2217. doi:10.1016/S0140-6736(15) 01284-2

3. Bauman AE. Updating the evidence that PA is good for health: an epidemiological review 2000-2003. J Sci Med Sport. 2004;7:6-19. doi:10.1016/S1440-2440(04)80273-1

4. Warburton DE, Nicol CW, Bredin SS. Health benefits of physical activity: the evidence. CMAJ. 2006;174(6):801-809. PubMed ID: 16534088 doi:10.1503/cmaj.051351 
5. Kohl HW. PA and cardiovascular disease: evidence for a dose response. Med Sci Sports Exerc. 2001;33:S472-483. PubMed ID: 11427773

6. Maas J, Vandillen SME, Verheij RA, Groenewegenand PP. Social contacts as a possible mechanism behind the relation between green space and health. Health Place. 2009;15:586-595. PubMed ID: 19022699 doi:10.1016/j.healthplace.2008.09.006

7. Fan Y, Das KV, Chen Q. Neighborhood green, social support, physical activity, and stress: assessing the cumulative impact. Health Place. 2011;17(6):1202-1211. PubMed ID: 21920795 doi:10.1016/j. healthplace.2011.08.008

8. Sweirad EM, Huang TTK. An exploration of psychosocial pathways of parks' effects on health: a qualitative study. Int J Environ Res Public Health. 2018;15:1693. doi:10.3390/ijerph15081693

9. Cohen DA, McKenzie TL, Sehgal A, Williamson S, Golinelli D, Lurie N. Contribution of public parks to PA. Am J Public Health. 2007;97(3):509-514. PubMed ID: 17267728 doi:10.2105/AJPH. 2005.072447

10. Van Hecke L, Verhoeven H, Clarys P, et al. Factors related with public open space use among adolescents: a study using GPS and accelerometers. Int J Health Geogr. 2018;17(1):3. doi:10.1186/ s12942-018-0123-2

11. Jennings V, Johnson Gaither C. Approaching environmental health disparities and green spaces: an ecosystem services perspective. Int $J$ Environ Res Public Health. 2015;12(2):1952-1968. PubMed ID: 25674782 doi:10.3390/ijerph120201952

12. Jennings V, Baptiste AK, Osborne JN, Skeete R. Urban green space and the pursuit of health equity in parts of the United States. Int $J$ Environ Res Public Health. 2017;14(11):1432. doi:10.3390/ijerph 14111432

13. Engelberg JK, Conway TL, Geremia C, et al. Socioeconomic and race/ethnic disparities in observed park quality. BMC Public Health. 2016;16:395. PubMed ID: 27176854 doi:10.1186/s12889-0163055-4

14. Park S, Han B, Cohen DA, Derose KP. Contributions of neighborhood parks to physical activity in high-poverty urban neighborhoods. J Urban Health. 2018;95(6):881-887. PubMed ID: 30324357 doi: $10.1007 / \mathrm{s} 11524-018-0320-0$
15. Alberico CO, Hipp JA, Reis RS. Association between neighborhood income, patterns of use, and physical activity levels in fitness zones of Curitiba, Brazil. J Phys Act Health. 2019;16(6):447-454. PubMed ID: 31023140 doi:10.1123/jpah.2018-0234

16. Cohen DA, Han B, Nagel CJ, et al. The first national study of neighborhood parks: implications for PA. Am J Prev Med. 2016; 54(4):419-426. doi:10.1016/j.amepre.2016.03.021

17. Cohen DA, Han B, Derose KP, Williamson S, Marsh T, McKenzie TL. Physical activity in parks: a randomized controlled trial using community engagement. Am J Prev Med. 2013;45(5):590-597. PubMed ID: 24139772 doi:10.1016/j.amepre.2013.06.015

18. Cavill N, Bauman A. Changing the way people think about healthenhancing PA: do mass media campaigns have a role? J Sports Sci. 2004;22:771-790. PubMed ID: 15370487 doi:10.1080/0264 0410410001712467

19. Cohen DA, Han B, Derose KP. Promoting physical activity in highpoverty neighborhood parks: a cluster randomized controlled trial. Soc Sci Med. 2017;186:130-138. doi:10.1016/j.socscimed.2017. 06.001

20. Bush CL, Pittman S, McKay S, Ortiz T, Wong WW, Klish WJ. Parkbased obesity intervention program for inner-city minority children. J Pediatr. 2007;151(5):513-517. PubMed ID: 17961696 doi:10. 1016/j.jpeds.2007.04.008

21. Twisk J, Bosman L, Hoekstra T, Rjinhart J, Welten M, Heymans M. Different ways to estimate treatment effects in randomised controlled trials. Contemp Clin Trials Commun. 2018;10:80-85. doi:10.1016/j. conctc. 2018.03.008

22. Vickers AJ, Altman DG. Analysing controlled trials with baseline and follow up measurements. Br Med J. 2001;323:1123. doi:10.1136/ bmj.323.7321.1123

23. Athey S, Imbens GW. The econometrics of randomized experiments. In: Duflo E, Banerjee A, eds. Handbook of Economic Field Experiments. 2017;1:73-140. doi:10.1016/bs.hefe.2016.10.003

24. Kahn EB, Ramsey LT, Brownson RC, et al. The effectiveness of interventions to increase PA: a systematic review. Am J Prev Med. 2002;22(4):73-107. doi:10.1016/S0749-3797(02)00434-8

25. Sherer PM. Why America Needs More City Parks and Open Space. San Francisco, CA: The Trust for Public Land. 2003;1-32. 